\title{
Should we rely on Doppler measurements in assessment of degenerative mitral stenosis?
}

\section{Zvonimir Ostojić* Vlatka Rešković Lukšić,}

\section{Jadranka Šeparović Hanževački}

University of Zagreb School of Medicine, University Hospital Centre Zagreb, Zagreb,

Croatia
RECEIVED:

March 11, 2017

ACCEPTED:

April 6, 2017

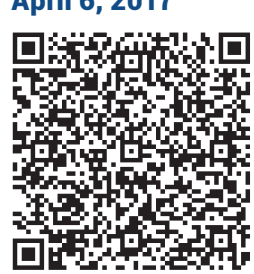

KEYWORDS: mitral stenosis, Doppler echocardiography, 3D echocardiography. CITATION: Cardiol Croat. 2017;12(4):125-126. | https://doi.org/10.15836/ccar2017.125

*ADDRESS FOR CORRESPONDENCE: Zvonimir Ostojić, Klinički bolnički centar Zagreb, Kišpatićeva 12, HR-10000 Zagreb, Croatia. / Phone: +385-91-895-0702 / E-mail: ostojiczvonimir@gmail.com

ORCID: Zvonimir Ostojić, http://orcid.org/0000-0003-1762-9270 • Vlatka Rešković Lukšić, http://orcid.org/0000-0002-4721-3236 Jadranka Šeparović Hanževački, http://orcid.org/0000-0002-3437-6407

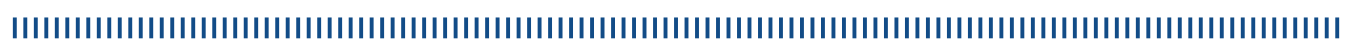
Introduction: Compared to rheumatic mitral stenosis (RMS), degenerative mitral stenosis (DMS) is usually described as less sever. For the severity assessment echocardiographic Doppler parameters are often used, despite the well known possibility of DMS severity underestimation due to the influence myocardial diastolic function and concomitant valve patohlogy ${ }^{1,2}$ The aim of this study was to compare severity of DMS compared to RMS and to determine whether Doppler parameters underestimate severity of DMS compared to other echocardiographic measurements.

Methods: We preformed a single center, retrospective, observational study including all patients who were diagnosed with mitral stenosis in past three years. Data were reanalyzed using fully digital echocardiographic database and hospital charts. Mitral stenosis (MS) was defined as turbulent flow with mean diastolic gradient $>2 \mathrm{mmHg}$ across mitral valve (MV) in conjunction with morphologic changes. In patients who had 3D examinations made, mitral valve area (MVA) was calculated according to pressure half time (PHT), continuity equation, 3D transthoracic echocardiography, and 3D transoesophageal echocardiography.

Results: Patients with DMS ( $\mathrm{N}=38$, female $\mathrm{N}=23 ; 60.5 \%$ ) compared to patients with RMS were significantly older ( $80 \pm 9.4$ vs. $67 \pm 7.1 ; p<0.001$ ), with more pronounced risk factors for worse cardiovascular outcome (more hyperlipidemia, worse renal function, and coronary artery disease). Patients with RMS $(\mathrm{N}=47)$ had significantly higher rate of atrial fibrillation (47 vs. $35 \% ; p=0.005)$. According to echocardiographic data patients with DMS had significantly higher left ventricular mass and increased relative wall thickness. They also had more sever and pronounced mitral annular calcification spread to both cusps. Patients with RMS had significantly larger left atrium area (LAA). In line with degenerative process, significant aortic steno-
TABLE 1. Echocardiographic findings depending on etiology of mitral stenosis.

\begin{tabular}{|c|c|c|c|}
\hline & Degenerative & Rheumatic & $\mathbf{P}$ \\
\hline IVSd (cm) $^{1}$ & $1.38 \pm 0.35$ & $1.14 \pm 0.25$ & $<0.001$ \\
\hline $\operatorname{LVIDd}(\mathbf{c m})^{2}$ & $4.93 \pm 0.68$ & $5.06 \pm 0.59$ & 0.36 \\
\hline LVPWd $(\mathrm{cm})^{3}$ & $1.22 \pm 0.30$ & $1.02 \pm 0.21$ & $<0.001$ \\
\hline Left ventricular mass (g) & $267.37 \pm 89.11$ & $212.14 \pm 58.46$ & $<0.001$ \\
\hline Relative wall thickness & $0.51 \pm 0.15$ & $0.41 \pm 0.1$ & $<0.001$ \\
\hline Ejection fraction & $56 \pm 8$ & $55 \pm 7.6$ & 0.58 \\
\hline Mitral annular calcification ${ }^{4}$ & 2.45 & 1.46 & $<0.001$ \\
\hline Mean pressure gradient & $5.89 \pm 2.91$ & $7.9 \pm 4.8$ & 0.02 \\
\hline Maximal pressure gradient & $14.21 \pm 5.4$ & $18 \pm 8.3$ & 0.01 \\
\hline MVA PHT 5 & $1.92 \pm 0.76$ & $1.55 \pm 0.38$ & 0.02 \\
\hline MVA VTI ${ }^{6}$ & 1.26 & 1.26 & 0.07 \\
\hline LAA $^{7}$ & $34.24 \pm 7.6$ & $42.77 \pm 17.23$ & 0.004 \\
\hline $\mathrm{MI} \geq 2^{8}$ & $11(29 \%)$ & $20(42 \%)$ & 0.19 \\
\hline AS $\geq 2^{9}$ & $30(79 \%)$ & $15(32 \%)$ & $<0.001$ \\
\hline $\mathrm{Al} \geq 2^{10}$ & $5(13 \%)$ & $10(21 \%)$ & 0.32 \\
\hline $\mathrm{TI} \geq 2^{11}$ & $8(21 \%)$ & $16(34 \%)$ & 0.18 \\
\hline $\mathrm{PH}^{12}$ & $48 \pm 18$ & $55 \pm 22$ & 0.2 \\
\hline TAPSE $^{13}$ & $17.8 \pm 4.8$ & $17.7 \pm 5.3$ & 0.9 \\
\hline
\end{tabular}

IIntraventricular septal width in diastole; ${ }^{2}$ Left ventricle internal dimension in diastole; ${ }^{3}$ Left ventricle posterior wall width in diastole; ${ }^{4}$ Mitral annulus calcification: 1 - annular calcification; 2 - calcification extend $<1 / 2$ of mitral cusp; 3 - calcification extend $>1 / 2$ of mitral cusp; ${ }^{5}$ Mitral valve area calculated using pressure half time; ${ }^{6}$ Mitral valve area calculated using velocity time integral; ${ }^{7}$ Left atrium area; ${ }^{8}$ Mitral insufficiency at least moderate in severity; ${ }^{9} \mathrm{Aortic}$ stenosis at least moderate in severity; ${ }^{10} \mathrm{Aortic}$ insufficiency at least moderate in severity; "Tricuspid insufficiency at least moderate in severity; ${ }^{2}$ Systolic pressure in pulmonary artery; ${ }^{13}$ Tricuspid annular plane systolic excursion. 
sis (AS), defined to be at least moderate in severity, was more common in DMS group with no significant difference in other concomitant valve pathology (Table 1). Total 35 patients had MVA assessed using 3D planimetry. There was a significant difference in MVA when measured by PHT according to other methods irrespectively of MS etiology. In all cases MS was underestimated by PHT (Table 2).

Conclusion: As expected, patients with DMS are older, with higher rate of comorbidities and higher prevalence of significant AS. On the other hand, patients with RMS had larger LAA and more often AF. Our results indicate that Doppler assessment of MS, using PHT, significantly underestimates severity of MS in DMS patients when compared with other methods, especially 3D planimetry. Furthermore, the same observations are described in our group of patients with RMS. In our opinion, cause of misleading PHT measurement might be of different cause between groups, but this requires further studies.

\section{TABLE 2. Comparison of calculated mitral valve area with different echocardio-}

\section{graphic methods.}

\begin{tabular}{|c|c|c|c|c|c|c|}
\hline \multirow{4}{*}{ MVA' calculation } & $\mathrm{PHT}^{2}$ & PHT & PHT & VTI & VTI & 3D TTE \\
\hline & $1.83 \pm 0.64$ & $1.83 \pm 0.64$ & $1.83 \pm 0.64$ & $1.46 \pm 0.49$ & $1.46 \pm 0.49$ & $1.32 \pm 0.45$ \\
\hline & $\left.\mathrm{VT}\right|^{3}$ & 3D TTE ${ }^{4}$ & $3 \mathrm{D}$ TOE & 3D TTE & 3D TOE & 3D TOE \\
\hline & $1.46 \pm 0.49$ & $1.32 \pm 0.45$ & $1.20 \pm 0.42$ & $1.32 \pm 0.45$ & $1.20 \pm 0.42$ & $1.20 \pm 0.42$ \\
\hline$p$ value & $\mathrm{p}=0.019$ & $p=0.013$ & $p<0.001$ & $\mathrm{p}=0.557$ & $p=0.074$ & $p=0.491$ \\
\hline
\end{tabular}

2. Pasca I, Dang P. Tyagi G, Pai RG. Survival in Patients with Degenerative Mitral Stenosis: Results from a Large Retrospective Cohort Study. J Am Soc Echocardiogr. 2016 May;29(5):461-9. https://doi.org/10.1016/j.echo.2015.12.012 